\title{
Epigenetic dynamics and interplay during spermatogenesis and embryogenesis: implications for male fertility and offspring health
}

\author{
Shao-Qin Ge ${ }^{1,2,3,4}$, Sheng-Li Lin ${ }^{5}$, Zheng-Hui Zhao ${ }^{6,7}$ and Qing-Yuan Sun ${ }^{6,7}$ \\ ${ }^{1}$ Hebei University Health Science Center, Baoding, China \\ 2 Institute for Reproductive Medicine of Hebei University, Baoding, China \\ ${ }^{3}$ Center for Reproductive Medicine of Affiliated Hospital of Hebei University, Baoding, China \\ ${ }^{4}$ Hebei Research Institute for Family Planning, Shijiazhuang, China \\ ${ }^{5}$ The Center for Reproductive Medicine of Peking University Third Hospital, Beijing, China \\ ${ }^{6}$ State Key Laboratory of Stem Cell and Reproductive Biology, Institute of Zoology, Chinese Academy of Sciences, Beijing, \\ China \\ ${ }^{7}$ University of Chinese Academy of Sciences, Beijing, China \\ Correspondence to: Qing-Yuan Sun, email: sunqy@ioz.ac.cn \\ Keywords: epigenetic modifications, intergenerational inheritance, spermatogenesis, embryogenesis, reproductive diseases \\ Received: March 12, $2017 \quad$ Accepted: April 14, $2017 \quad$ Published: April 27, 2017
}

Copyright: Ge et al. This is an open-access article distributed under the terms of the Creative Commons Attribution License 3.0 (CC BY 3.0 ), which permits unrestricted use, distribution, and reproduction in any medium, provided the original author and source are credited.

\section{ABSTRACT}

Mapping epigenetic modifications and identifying their roles in the regulation of spermatogenesis and embryogenesis are essential for gaining fundamental medical understandings and for clinical applications. More and more evidence has shown that specific epigenetic modifications are established during spermatogenesis, which will be transferred into oocyte via fertilisation, and play an important role in the early embryo development. Defects in epigenetic patterns may increase the risk of abnormal spermatogenesis, fertilisation failure, early embryogenesis abnormality and several other complications during pregnancy. This review mainly discusses the relationship between altered epigenetic profiles and reproductive diseases, highlighting how epigenetic defects affect the quality of sperm and embryo.

\section{INTRODUCTION}

Epigenetic modifications such as DNA methylation, histone modifications, noncoding RNAs and protamine code are important regulators in a variety of reproductive processes [1-3]. To form highly specialised mature sperm and facilitate the totipotency of the zygote, these epigenetic modifications must undergo dramatic reprogramming to rearrange chromatin structure, and thus the spermatogenesis and early embryogenesis are particularly vulnerable to epigenetic perturbations [4]. Epigenetic alterations in reproductive processes could result in abnormal expression of target genes and further lead to some reproductive diseases, such as male infertility, early embryo development failure and/or other diseases with underlying epigenetic changes in offspring $[5,6]$.
Genome-wide profiles of epigenetic modifications have been generated for many different types of cells. Such studies are helpful for understanding the cell type changes during spermatogenesis and embryogenesis, and will provide possible therapeutic targets for the treatment of these reproductive diseases [7, 8]. Likewise, epigenetic biomarkers in sperm have a potential role in predicting and preventing certain diseases in offspring [9]. However, given the diversity and complexity of spermatogenesis and early embryogenesis, it is remaining unclear about the dynamics between distinct epigenetic modifications and links across cellular contexts, and the interplay mechanisms of epigenetic regulation are not well established [10]. This review focuses on the epigenetic profiles and their regulation during the spermatogenesis and embryogenesis processes, providing an overview of the current knowledge on the aetiology of male infertility at the epigenetic level. 


\section{Dynamics of epigenetic modifications and their interplay during spermatogenesis and embryogenesis}

Mammalian DNA methylation in cytosine is a critical epigenetic modification that plays crucial roles in transcriptional regulation, chromatin remodelling and genomic imprinting [11-13]. Dynamic erasure and reestablishment of DNA methylation marks catalysed by TET (ten-eleven translocation) dioxygenases and DNA methyltransferases (DNMTs) respectively, are required for the spermatogenesis and embryogenesis [14]. There are two main processes for DNA methylation reprogramming, the first reprogramming process occurs in the onset of spermatogenesis and the other begins at the early stage of embryogenesis (Figure 1). The proper regulation of DNA de novo methylation and demethylation is essential for normal function of the mature sperm and early embryo $[1,15]$.

In addition, changes of DNA methylation marks may partially rely on pre-existing histone modifications. In the process of de novo DNA methylation, the DNMT3A/B is recruited to $\mathrm{H} 3 \mathrm{~K} 9 \mathrm{me} 3$ through directly interacting with the HP1 (heterochromatin protein 1) that binds to H3K9me3 via its chromodomain, or indirectly interacting with the Suv39h1 and Setdb1 via their ADD domain at heterochromatin. At the euchromatin, the DNMT3A/B could combine with euchromatin-associated G9a via the MPP8 domain [16]. On the other hand, the H3K4me3 might be involved in blocking the de novo methylation, as the Dnmt3L contains an ADD domain that specifically binds only to the $\mathrm{H} 3 \mathrm{~K} 4 \mathrm{me}$, not to $\mathrm{H} 3 \mathrm{~K} 4 \mathrm{me} 3$ [16]. Moreover, the $\mathrm{H} 3 \mathrm{~K} 4 \mathrm{me} 0$ could bind to the ADD domain of the DNMT3A and stimulate the DNMT3A to undergo a significant conformational change from an inhibitory form to an active form [17]. Accordingly, it is speculated that the $\mathrm{H} 3 \mathrm{~K} 4 \mathrm{me} 3$ might participate in the DNMT3A activity decreased. In the process of DNA demethylation, the $\mathrm{H} 3 \mathrm{~K} 9 \mathrm{me} 0$ in paternal genome is maintained through binding with the HP1 and occluding the H3K9mel to prevent further DNA methylation [18]. However in a maternal genome, the DNA demethylation is prevented, since the PGC7 recognises the $\mathrm{H} 3 \mathrm{~K} 9 \mathrm{me} 2$ and therefore protects the maternal genome from the TET3-mediated hydroxylation. Interestingly, the $\mathrm{H} 3 \mathrm{~K} 9 \mathrm{me} 2$ also plays a key role in protecting a small subset of the paternal genome from the TET3-dependent cytosine demethylation [19]. In addition, the latest study has shown that the DNA maintenance methylation is largely independent of the H3K9 methylation [20].

As another major epigenetic factor, histone modifications also have critical roles in the establishment of global chromatin environments and orchestration of DNA based biological tasks. There are 16 types of modifications identified to date, which can be considered as biomarkers for both active and inactive regions of the chromatin [21]. In active regions, there are high levels of acetylation and trimethylation at the H3K4, H3K 36 and H3K79, while the H3K9, H3K27 and H4K20 methylations are associated with the transcriptional repression [22]. Dynamics of histone modifications are critical for the spermatogenesis and early embryogenesis (Figure 1). Each of these modifications works alone or jointly with others, under the name of 'histone code' to promote gene activation or inactivation via the disruption of contacts between nucleosomes or the recruitment of non-histone proteins [22]. After fertilisation, the noncanonical $\mathrm{H} 3 \mathrm{~K} 4 \mathrm{me} 3$ undergoes extensive reprogramming and its level is largely depleted from the early to the late 2-cell-stage embryo. Subsequently, the reestablishment of canonical $\mathrm{H} 3 \mathrm{~K} 4 \mathrm{me} 3$ occurs rapidly on promoter regions, and many promoters retain this modification till blastocyst stage. Meanwhile, H3K27me3 exhibits a massive loss from the late 2-cell-stage embryo to blastocyst. The distinct features of $\mathrm{H} 3 \mathrm{~K} 4 \mathrm{me} 3$ and $\mathrm{H} 3 \mathrm{~K} 27 \mathrm{me} 3$ are essential for zygotic genome activation and the further development [23-25]. As two major mechanisms for the epigenetic regulation, histone modifications and the DNA methylation are expected to regulate the gene expression co-ordinately via forming specific chromatin structures. In embryonic stem cells, the H3K27me3 is located in the discrete and punctate regions that are generally devoid of the DNA methylation [16]. From fertilisation to the two-cell stage, the level of H3K27me3 and maternal DNA methylation is high, but the paternal DNA methylation level is decreasing. Accordingly, we could speculate that the $\mathrm{H} 3 \mathrm{~K} 27 \mathrm{me} 3$ locates preferentially on the paternal genome and excludes from the DNA methylation. Interestingly, promoters that are marked with the H3K27me3 in embryonic stem cells are more likely to gain DNA methylation during the differentiation than those lacking H3K27me3 [16]. The detail mechanism between the $\mathrm{H} 3 \mathrm{~K} 27 \mathrm{me} 3$ and DNA methylation requires further research.

The non-coding RNAs (ncRNAs) represent an important epigenetic modification that exhibits seizes of transcripts and acts as controllers for the gene regulation $[26,27]$. They regulate gene expression at the transcriptional and post transcriptional level in different biological contexts and diseases. The miRNAs are 19-25 nucleotides long and involved in an orchestrated stage that specifically controls the gene expression [28]. The main epigenetic effect of miRNAs is to form a miRNA induced silencing complex (miRISC) in the germ granules, facilitating numerous downstream targeted gene silencing by the mRNA degradation or translational repressions (Figure 2). Moreover, miRNAs can also influence the epigenetic phenomena either directly by inhibiting the enzymes involved in the DNA methylation, histone modifications and chromatin remodelling or indirectly by altering the availability of substrates necessary for these 
enzymatic reactions [27-29]. Interestingly, the same epigenetic modifications regulated by miRNAs can also affect the miRNA expression [27]. For example, the miR$29 \mathrm{a}$ and $-29 \mathrm{~b}$ decreases the activities of the DNMT3A and DNMT3B, further impairing the de novo DNA methylation [29]. In addition, the miR-469 could degrade the transcripts of transition protein 2 and protamine 2 in pachytene spermatocytes and round spermatids, which are essential for the successful compaction of the sperm chromatin [30]. Further, some miRNAs are inheritable [31]. For example, the miR-34c is the most abundant in sperm and is also required for the early embryonic cell division through decreasing the expression of B-cell leukaemia/lymphoma 2 (Bcl-2) [32]. It is believed that these inherited miRNAs work with the newly established DNA methylation and histone modifications, to provide an appropriate epigenetic landscape for the embryogenesis.
piRNAs are 24-30 nucleotides, a single stranded RNAs that predominantly contribute to the spermatogenesis and embryogenesis in a stage specific manner [27, 33]. Generally, piRNAs are associated with the PIWI proteins and other adjuncts, to form the piRNA induced silencing complex (piRISC) in germ granules (Figure 3). Taking into account the expression patterns of piRNAs and PIWI proteins in male germ cells and early embryos, we believe that piRISC participates in the gene regulation at the transcriptional, post-transcriptional and even translational levels to some extent [34, 35]. The piRISC regulates gene silencing and maintains the genome stability through cleaving of the target mRNAs, or directing the DNA methylation dependent silencing towards target loci in the genome [36].

Transposable elements (TEs) are mobile genetic elements containing a high mutagenic potential when

A

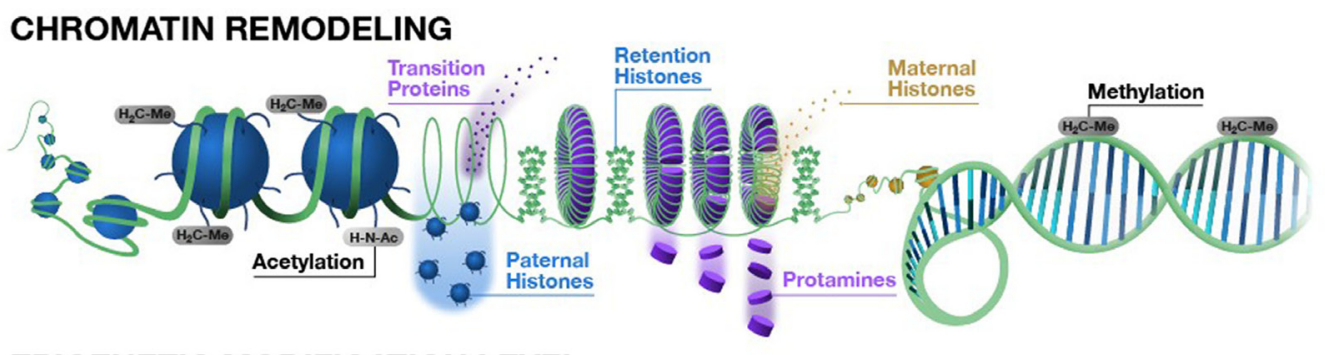

B

EPIGENETIC MODIFICATION LEVEL

Paternal DNA Methylation

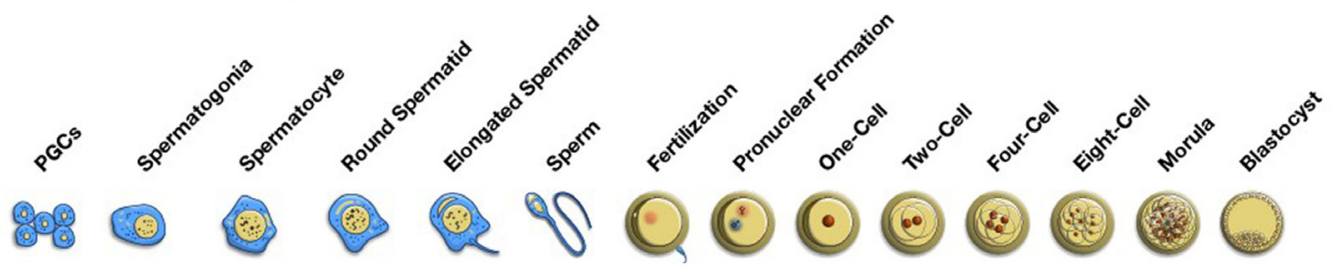

Maternal DNA Methylation

H3K4 Methylation

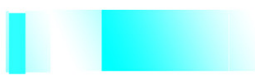

H3K9 Methylation

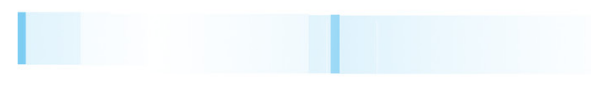

H3K27 Methylation

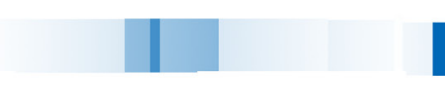

Figure 1: Chromatin remodeling and epigenetic modification changes during spermatogenesis, fertilisation and early embryo development. A. The process of chromatin remodeling during the spermatogenesis, fertilisation and embryogenesis. The process of chromatin remodeling mainly occurs with the condensation and decondensation of chromatin during spermeiogenesis and after fertilisation. During spermiogenesis from the spermatid to a sperm, the nucleus histones are replaced by the protamine, leading to the chromatin condensation, still with about $15 \%$ histone retention in the periphery of the nucleus. After fertilisation, before the pronuclear formation, the protamine-to-histone transition occurs, with the chromatin decondensation, the maternally derived histones replace the sperm protamines. B. The transformation of some epigenetic modifications during the spermatogenesis, fertilisation and embryogenesis. The transformations of some epigenetic modifications, including the DNA methylation, H3K4 methylation, H3K9 methylation and H3K27 methylation are essential for sperm production and early embryo development. These epigenetic modifications work cooperatively to regulate phase-specific gene expression that further controls key events in the processes of spermatogenesis, fertilisation and embryogenesis. 
Table 1: The abnormal DNA methylation and related diseases

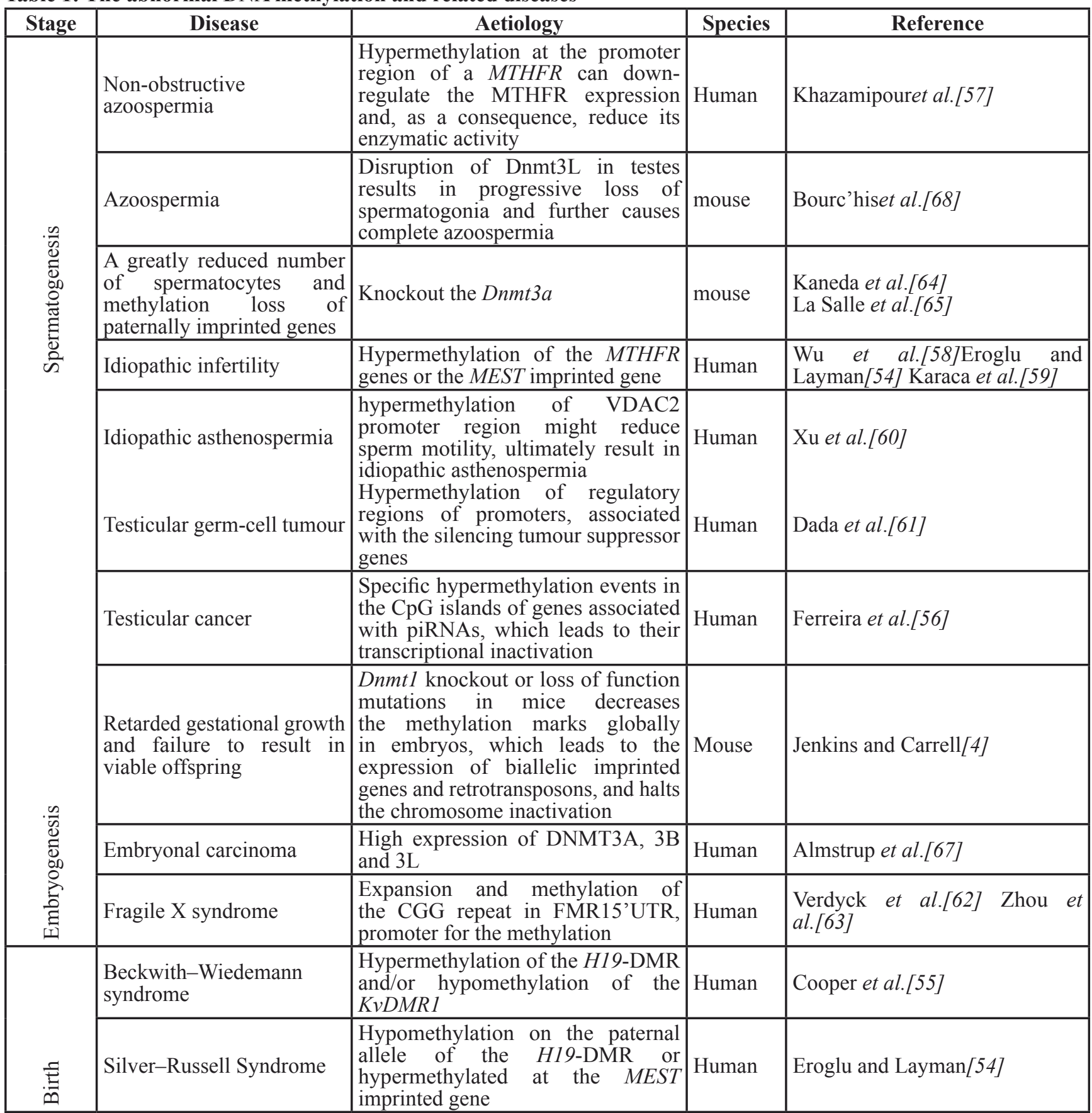

they are expressed unconstrainedly during gametes undergoing the epigenetic reprogramming [37]. Moreover, TEs are regulated by epigenetic modifications that are vulnerable to environmental factors, and such epigenetic information may contribute to environmentinduced intergenerational inheritance [38-40]. In the prospermatogonia, prepachytene piRNAs are necessary for silencing these mobile elements through guiding the de novo DNA methylation at the TEs to guarantee the genome stability [41]. In late spermatocytes and round spermatids, the pachytene piRNAs would be ideal for silencing the retrotransposon sequences through degrading the 3'UTR of retrotransposon mRNAs or recruiting the DNMT3L to the retrotransposon locus [42]. Immediately after fertilisation, both paternal and maternal genomes undergo an epigenetic reprogramming that is accompanied by a spike in retrotransposon expression [38]. piRNAs may protect the embryo from these deleterious elements through inducing epigenetic silencing of retroelements, further preventing the action of various classes of repetitive and transposable elements, including the SINE, LINE, MER and LTR [36, 43]. 
The histone retention and protamination are two unique processes that specifically exist in the spermiogenesis and early embryogenesis. Recent studies have demonstrated that the histone retention occurred at the spermatogenesis-associated genes, and the regions of retained histones lacked DNA methylation, which might facilitate sperm maturation and fertilisation [44]. Moreover, the retained histones also occurred at the specific developed gene loci and carried epigenetic structural information into early embryo, which might poise genes for activation at specific sites required for the normal embryogenesis [45]. In addition, histone modifications are involved in the retained regions. The $\mathrm{H} 3 \mathrm{~K} 4 \mathrm{me} 2$ becomes enriched at promoters of developmental genes and is involved in the spermatogenesis and cellular homeostasis, and the H3K4me3 appears at a subset of promoters of the highly expressed developmental genes, paternally expressed as the imprinted loci and the certain noncoding RNA promoters [46, 47]. Moreover, H3K4 methylation and
$\mathrm{H} 3 \mathrm{~K} 27 \mathrm{me} 3$ often co-occur in the histone retained regions, which is a mark involved in polycomb-mediated gene repression without promoting DNA methylation [48]. In addition, the histone variants are also abundant in the retained nucleosomes. Trimethylated histones H3.1 and $\mathrm{H} 3.2$ at $\mathrm{K} 27$ and histone $\mathrm{H} 3.3$ at K4 are enriched in these regions [49].

During spermiogenesis, the protamination plays important roles in the proper condensation of the sperm chromatin [45]. This process directs the histone to protamine transition and forms a structure of nucleosomes within the protamine toroids (Figure 1) that effectively protect the sperm genome against the DNA damage [50]. Recently, the histone variant $\mathrm{TH} 2 \mathrm{~B}$ was reported to participate in the protamination process. The TH2B could replace the $\mathrm{H} 2 \mathrm{~B}$ during the spermiogenesis, thereby changing the chromatin forms from histones to protamines [50]. Interestingly, the TH2B could also be involved in the chromatin destabilisation during the early stage of an embryonic development, facilitating the genome plasticity

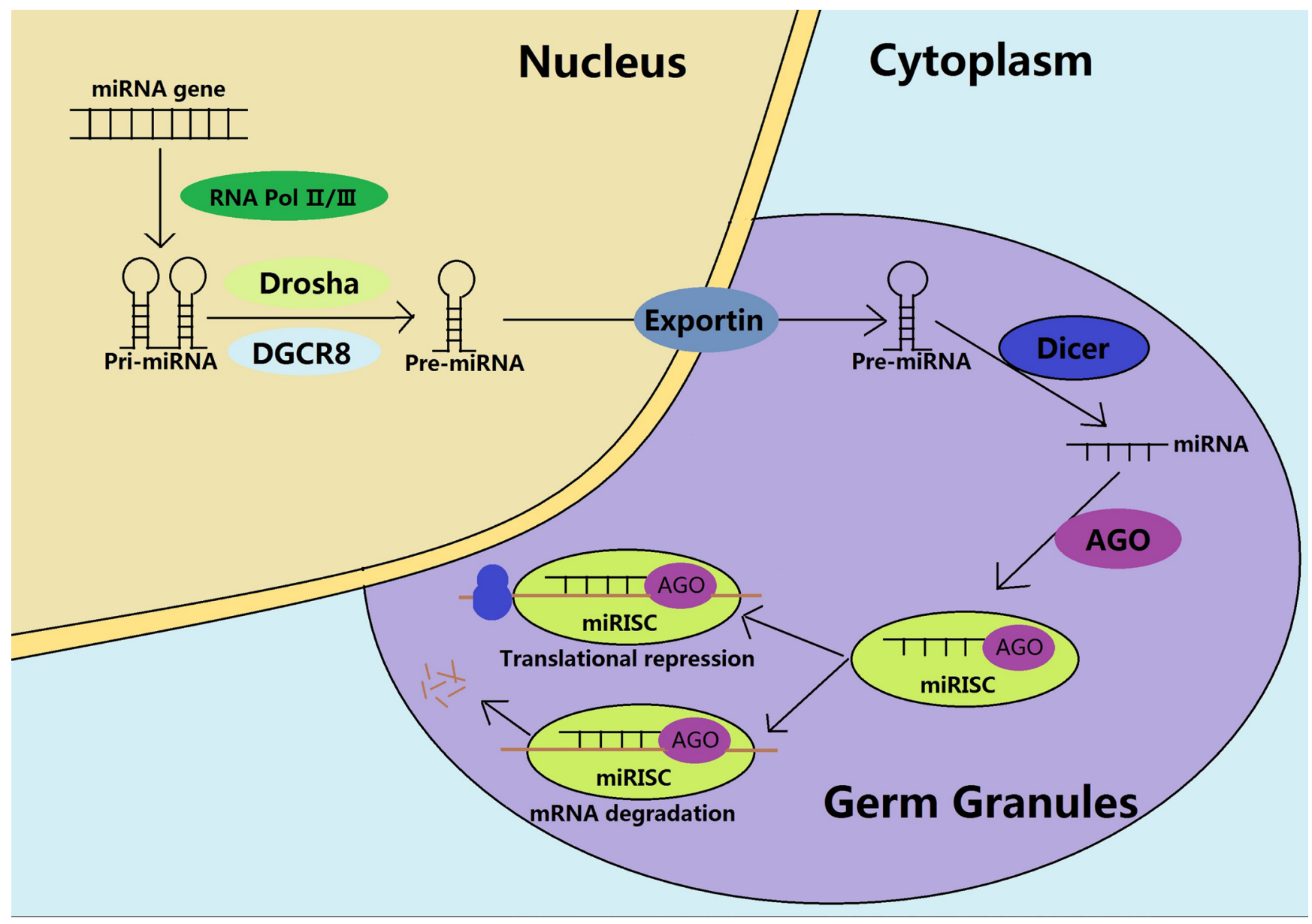

Figure 2: Biogenesis and functions of miRNAs during the spermatogenesis. In the nucleus, catalyzed by the RNA Pol II/ III, the pri-miRNAs are transcribed from the miRNA genes, and processed into pre-miRNAs through the Drosha and the DGCR8. The pre-miRNAs are subsequently exported to the germ cytoplasmic granules. After maturation by the Dicer, the mature miRNAs unwind and recruit the AGO protein to form a miRNA-induced silencing complex (miRISC), being involved in the mRNA degradation or translational repression, depending on the sequence similarity. 
Table 2: Abnormal histone modifications and associated diseases

\begin{tabular}{|c|c|c|c|c|}
\hline Stage & Disease & Aetiology & Species & Reference \\
\hline \multirow{6}{*}{ 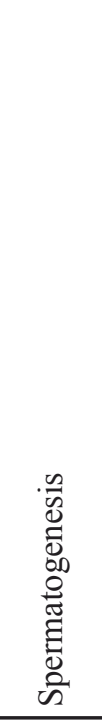 } & Decrease of spermatocytes & $\begin{array}{l}\text { The reduction of histone } \mathrm{H} 3 \mathrm{~K} 4 \text { methyltransferase } \\
\text { MII2 activity }\end{array}$ & Mouse & Glaser et al.[69] \\
\hline & $\begin{array}{l}\begin{array}{l}\text { Sperm apoptosis and } \\
\text { sterility }\end{array} \\
\end{array}$ & The loss of LSD1/KDM1 & Human & Shi et al.[70] \\
\hline & $\begin{array}{l}\text { Impaired post meiotic } \\
\text { chromatin condensation }\end{array}$ & $\begin{array}{l}\text { Deficiency of the JHMD2A can down regulate the } \\
\text { expression of two genes, the P1 and TNP1, leading } \\
\text { to the condensation and proper packaging of the } \\
\text { chromatin failure in sperms }\end{array}$ & Mouse & Najafipour et al.[71] \\
\hline & $\begin{array}{l}\text { Inhibit the process of } \\
\text { spermatogenesis }\end{array}$ & Altered dimethylation states of the H3K9 & Mouse & Xiong et al.[74] \\
\hline & $\begin{array}{l}\text { Nucleosome } \\
\text { abnormality }\end{array}$ & $\begin{array}{l}\text { Deficiency of the RNF8, a ubiquitin ligase, could } \\
\text { lead to the abnormal H4K16 acetylation that } \\
\text { significantly suppresses the histone removal and } \\
\text { results in the incorporation of the transition protein }\end{array}$ & Mouse & Lu et al.[72] \\
\hline & $\begin{array}{l}\text { Partial failure in chromatin } \\
\text { condensation, abnormal } \\
\text { sperm head morphology, } \\
\text { immotility of epididymal } \\
\text { sperm, and male infertility }\end{array}$ & $\begin{array}{l}\text { Knockout Chd5, a gene encoding chromatin- } \\
\text { remodeling nuclear protein, decreases the H4 } \\
\text { hyperacetylation in elongating spermatids }\end{array}$ & Mouse & Zhuang et al.[73] \\
\hline \multirow{3}{*}{ 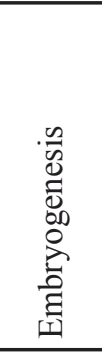 } & $\begin{array}{l}\text { Insufficient sperm } \\
\text { chromatin compaction that } \\
\text { persists in the zygote }\end{array}$ & $\begin{array}{l}\text { Aberrant acetylation of the } \mathrm{H} 4 \mathrm{~K} 12 \text { in promoters of } \\
\text { the development of important genes }\end{array}$ & Human & $\begin{array}{l}\text { Paradowska } \\
\text { al. }[75]\end{array}$ \\
\hline & $\begin{array}{l}\text { Less developmentally } \\
\text { competent embryos }\end{array}$ & $\begin{array}{l}\text { abnormal expression of BRG1 and KDM1A around } \\
\text { the period of embryonic genome activation could } \\
\text { alter the } \mathrm{H} 3 \mathrm{~K} 4 \text { methylation }\end{array}$ & Porcine & Glanzneret al.[76] \\
\hline & Peri-implantation lethality & $\begin{array}{l}\text { Absence of the ERG-associated protein with the } \\
\text { SET domain, a histone methyltransferase that } \\
\text { specifically trimethylates the H3K9 residue }\end{array}$ & Mouse & Dodge et al.[77] \\
\hline 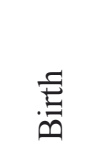 & Rubinstein-Taybi syndrome & $\begin{array}{l}\text { Acetylation of histones alters the folding of the } \\
\text { chromatin nucleoprotein complex }\end{array}$ & Human & Ausio et al.[78] \\
\hline
\end{tabular}

[45]. In addition, the protamine code also contributed to the transcriptional regulation by modulating interactions between protamines and the DNA sequences [45]. During the spermiogenesis process, acetylation and methylation can co-occur on a given protamine, whilst the acetylation and phosphorylation appear to be exclusive to each other [45]. When incorporated into chromatin, the protamines were immediately phosphorylated, which is essential for binding the protein to the DNA. However, once bound to the DNA, the protamines were dephosphorylated, for the proper condensation of chromatin [51]. Mukherjee et al. showed that the acetylation of residues $P 1 S 42$ and $P 2$ $S 55$ could be modified by post-translational modifications, which likely prevented their phosphorylation, providing a possible mechanism for the protamine dephosphorylation [52]. On the other hand, the sperm nucleus remodels extensively in early embryos through replacing the protamines with acetylated histones derived from the maternal genome, leading to the decondensation of the paternal chromatin (Figure 1). This process is the key for generating a transcriptionally competent DNA that helps to facilitate the needs of a zygote [1]. It will be interesting to investigate whether the protamine code serve any function in early embryonic development [46].

\section{ALTERATION OF EPIGENETIC MODIFICATIONS AND CORRESPONDING DISEASES}

Dynamic activation and inactivation of gene expression are essential for driving the differentiation of male germ cells and for the development of early embryos. Identifying the mechanisms of epigenetic regulation is necessary to understand how these fascinating systems contribute to the spermatogenesis and embryogenesis, and how these processes are disrupted in reproductive diseases [10]. The regulation of gene expression is mediated by many epigenetic factors, and abnormalities of these epigenetic profiles may lead to reproductive diseases. 


\section{Abnormal sperm DNA methylation in male infertility and embryogenesis defects}

The DNA methylation patterns acquired during spermatogenesis are necessary for a proper sperm production, the fertility and embryo development, and their alterations are closely related to male reproductive health, which can also affect the development of the embryo (Table 1) [6, 53]. Assisted reproductive techniques (ART), especially introcytoplasmic sperm injection, can be applied to treat male infertility by collecting morphology qualified sperm, but this may result in high epigenetic risk for offspring diseases mainly owing to the use of sperm with imprinting disorders. For example, the hypermethylation of the MEST-imprinted gene results in the idiopathic infertility for men with a normal sperm morphology below $5 \%$ and a progressive sperm motility below $40 \%$, which at least is partly contributed to the Silver-Russell Syndrome (SRS) [54]. There are two differentially methylated regions (DMRs), the H19 DMR and KvDMR1, located on the chromosome 11p15. The hypermethylation of the H19 DMR and/or hypomethylation of the KvDMR1 may result in the Beckwith-Wiedemann syndrome (BWS) [55]. Conversely, the hypomethylation of the paternal H19 DMR may lead to the SRS [54]. Therefore, high epigenetic quality sperm preparation may be a potential way to reduce the risk of epigenetic diseases, which emphasizes the importance of evaluation on the sperm quality in in both genetic and epigenetic levels. On the other hand, some diseases also result from the aberration of DNA methylation in some specific genes. Ferreira et al. reported that the specific hypermethylation events in the $\mathrm{CpG}$ islands of genes associated with the piRNAs could lead to their transcriptional suppression, which is considered to be a cause of the testicular cancer [56].

The methylation state of promoter in the genes involved in the spermatogenesis and early embryogenesis is a recent topic of interest. The hypermethylation at the promoter region of the MTHFR has shown to down regulate the MTHFR expression, and as a result its enzymatic activity is reduced, leading to non-

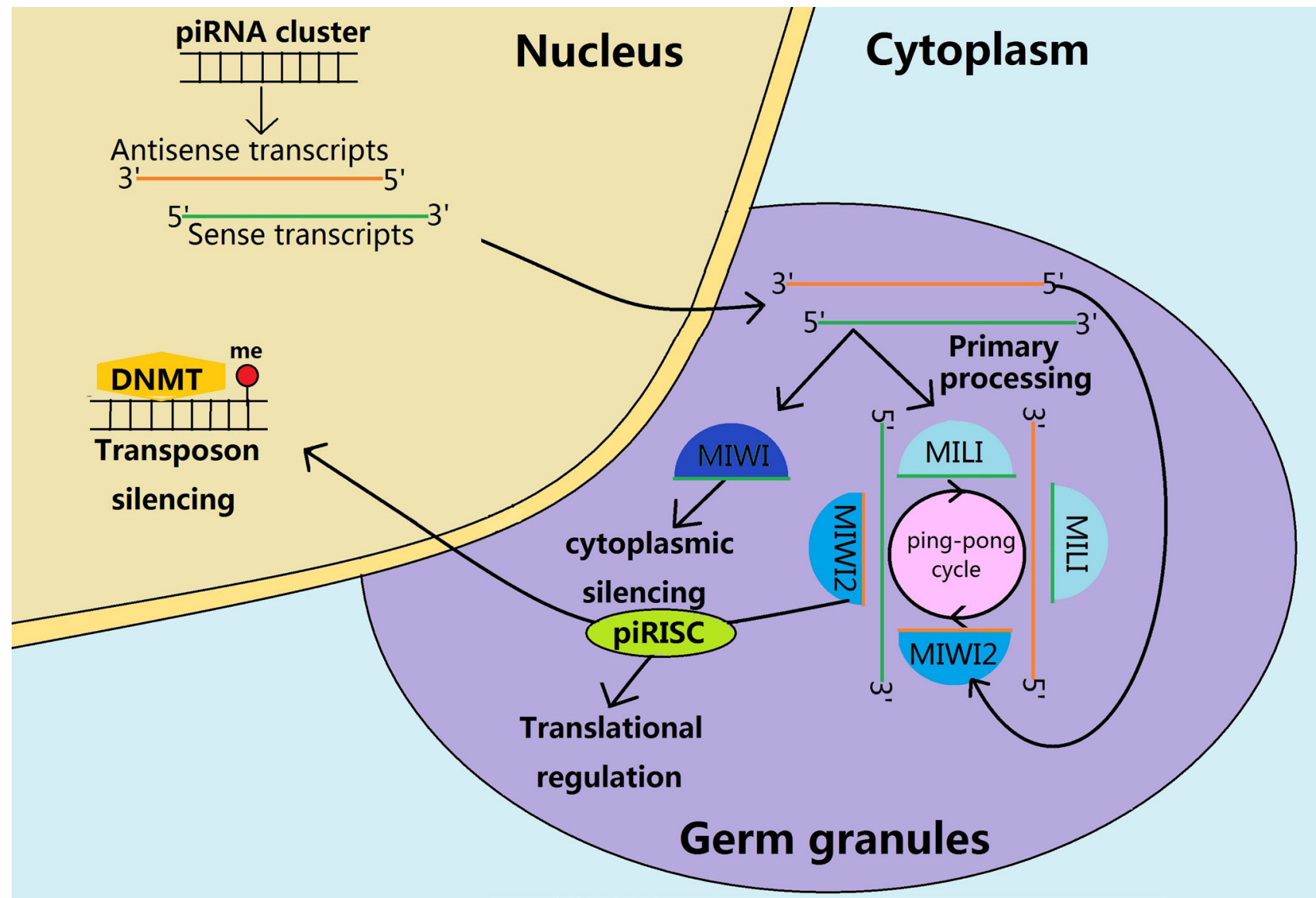

Figure 3: Biosynthesis and functions of piRNAs during the mouse spermatogenesis. The sense and antisense piRNA precursors are transcribed from the piRNA clusters in the nucleus and transported to the cytoplasm for further processing in the cytoplasmic germ granules. In a fetal prospermatogonia, the prepachytene piRNAs form piRNA induced silencing complex (piRISC) through the primary processing and the subsequent ping-pong cycle. Subsequently, piRISC participates in translational regulation in cytoplasm and transposon silencing in the nucleus through guiding de novo DNA methylation. After birth, the MIWI2 is no longer expressed but the MIWI appears to have contributed to the cytoplasmatic silencing through primary processing to produce the pachytene piRNAs. 
Table 3: Abnormal non-coding RNAs and male infertility

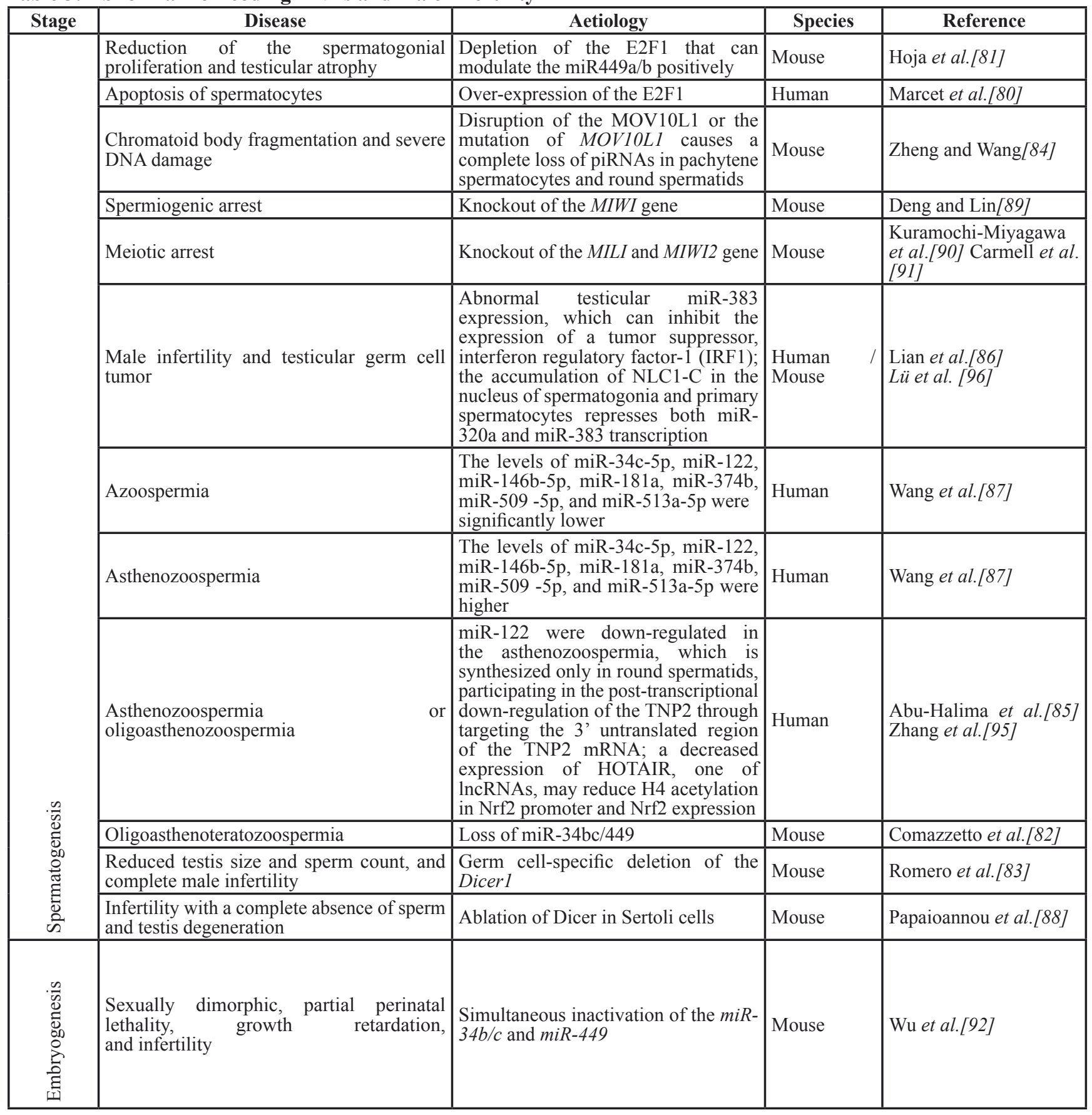

obstructive azoospermia (NOA) and potentially idiopathic infertility [57-59]. Likewise, hypermethylation of VDAC2 promoter region might reduce sperm motility, ultimately result in idiopathic asthenospermia [60]. In the regions of regulatory promoters, which are associated with the silencing of tumour suppressor genes, the hypermethylation can lead to testicular germ cell tumours [61]. Recently, Verdyck et al. have confirmed that the expansion of a CGG repeat tract and retained DNA methylation in the FMR1 5'UTR promoter resulted in the Fragile $\mathrm{X}$ syndrome $[62,63]$.
In addition, the disruption of DNMTs also resulted in the aberrant DNA methylation profiles clearly, and is associated with some diseases. For an instance, knockout the Dnmt3a could greatly reduce the number of spermatocytes and resulted in the methylation loss of paternally imprinted genes $[64,65]$. Further, the Dnmt $3 a$ and Dnmt $3 b$ knockout experiments have shown that the loss of the DNMT3B could lead to the loss of methylation at a single, specific locus that is absent in the Dnmt3a conditional knockouts, indicating there was much redundancy for the DNMT3B function [66]. In contrast, 
Table 4: Reduced male fertility with an abnormal proportion of protamines

\begin{tabular}{|c|c|c|c|c|}
\hline Stage & Disease & Aetiology & Species & Reference \\
\hline \multirow{5}{*}{ 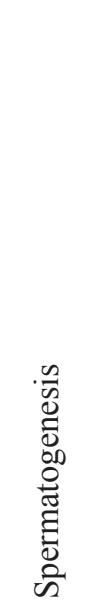 } & $\begin{array}{l}\text { Precocious chromatin } \\
\text { condensation, transcription arrest, } \\
\text { and spermatogenic failure }\end{array}$ & Deregulation of protamines & Mouse & Cho et al.[5] \\
\hline & Sperm DNA fragmentation & Abnormally high or low $\mathrm{P} 1 / \mathrm{P} 2$ ratios & Human & $\begin{array}{l}\text { Simon et al. [98, 99, } \\
\text { 100] }\end{array}$ \\
\hline & Lowered sperm counts & Haploinsufficiency of protamines & Mouse & Castillo et al.[100] \\
\hline & Male infertility & $\begin{array}{l}\text { The depletion of P2 leads not only to } \\
\text { impaired histone to protamine exchange } \\
\text { and disturbed DNA-hypercondensation, but } \\
\text { also to severe membrane defects resulting } \\
\text { in immotility }\end{array}$ & Mouse & Schneider et al.[101] \\
\hline & Asthenozoospermia & $\begin{array}{l}\text { lower levels of } \mathrm{P} 1 \text { and } \mathrm{P} 2 \text { transcripts or } \mathrm{P} 1 / \\
\mathrm{P} 2 \text { ratio }\end{array}$ & Human & Kempisty et al.[99] \\
\hline \multirow{2}{*}{ 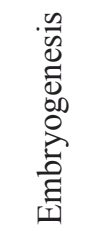 } & Lower pregnancy rates & Abnormal protamine replacement & Mouse & Cho et al.[5] \\
\hline & Embryo lethality & Low $\mathrm{P} 2$ concentrations & Mouse & Cho et al.[5] \\
\hline
\end{tabular}

a high expression of the DNMT3A and 3B, as well as their homologue $3 \mathrm{~L}$, was closely related to the embryonic carcinoma [67]. The disruption of the Dnmt3L in testes resulted in a progressive loss of the spermatogonia, and further caused a complete azoospermia [68]. The Dnmt1 knockout or loss of function mutations in mice may reduce the global methylation marks in the embryo, and the expression of the biallelic imprinted genes and retrotransposons were initiated, subsequently embryos exhibited a retarded gestational growth and did not result in a viable offspring [4].

\section{Abnormal histone modifications associated with male infertility and embryogenesis defects}

Histone modifications are shown to have a significant effect on the epigenetic regulation. Specific enzymes are necessary to orchestrate these modifications in sperm and embryos. As a result, the disruption of methylation or acetylation status of histones led to a various degrees of fertility and embryonic loss (Table 2). In addition, the apoptosis, sterility, failure of chromatin condensation, and the peri-implantation lethality are also linked with the perturbation of specific enzymes on the histones [69].

In the mitosis during spermatogenesis, the reduction of the MLL2 activity, a histone methyltransferase that is specific to the $\mathrm{H} 3 \mathrm{~K} 4$, could significantly decrease the number of spermatocytes through an apoptotic process [69]. During the meiosis, the loss of the LSD1/KDM1, which is histone demethylases specific to $\mathrm{H} 3 \mathrm{~K} 4$, could result in the apoptosis of sperm, leading to male sterility [70]. During the spermiogenesis, deficiency of the JHDM2A in mice, a histone demethylase specific to the $\mathrm{H} 3 \mathrm{~K}$ 9, could down regulate the gene expression of the transition protein 1 and protamine 1 [71]. Moreover, deficiency of the RNF8, a ubiquitin ligase, could lead to an abnormal H4K16 acetylation that significantly suppresses the histone removal, and resulted in the transition protein incorporation, leading to the nucleosome removal abnormality [72]. Similarly, knockout the Chd5, a gene encoding chromatin-remodeling nuclear protein, would decrease the $\mathrm{H} 4$ hyperacetylation in elongating spermatids and further gave rise to a partial failure of the chromatin condensation, abnormal sperm head morphology, immotility of epididymal sperm, and male infertility [73]. In addition, altering the states of the H3K9me 2 would inhibit the process of spermatogenesis [74]. All of these abnormal histone modifications have been confirmed to be causes of the defective chromatin condensation and infertility.

During the early stages of an embryogenesis, the aberrant acetylation of $\mathrm{H} 4 \mathrm{~K} 12$ promoters can reduce the sperm chromatin relaxation, resulting in the zygotic arrest [75]. In addition, decreased expressions of BRG1 and KDM1A around the period of embryonic genome activation could alter the $\mathrm{H} 3 \mathrm{~K} 4$ methylation and further result in less developmentally competent embryos [76]. Likewise, the absence of ERG associated with the protein, a histone methyltransferase specifically trimethylating the $\mathrm{H} 3 \mathrm{~K} 9$ residue, have caused the peri-implantation lethality [77]. For example, folding the chromatin nucleoprotein complex altered by the histone acetylation has been 
considered as a cause for the Rubinstein-Taybi syndrome [78].

\section{Abnormal noncoding RNAs associated with male infertility}

The spermatogenic process is a complex differentiation procedure that is prone to errors [79]. The expression of miRNAs and piRNAs during the spermatogenesis and embryogenesis is significant for the proper production and development of sperm and embryo, respectively. Their altered profiles in the spermatogenesis could result in the male infertility, and may be related to the testicular cancer (Table 3).

The expression of $\mathrm{miR} 449 \mathrm{a} / \mathrm{b}$ is positively modulated by the E2F transcription factor 1 (E2F1). Over expression of the miR449a/b would increase the apoptosis of spermatocytes, and reduce the depletion of E2F1 for the spermatogonial proliferation, further resulting in the testicular atrophy $[80,81]$. In contrast, the loss of miR449 may lead to oligoasthenoteratozoospermia [82]. On the other hand, the germ cell-specific deletion of Dicer 1 could reduce the testis size, sperm count, and complete male infertility [83]. During the pachytene spermatocyte stage, the disruption of MOV10L1, an RNA helicase, may induce a complete loss of the piRNAs, resulting in the chromatoid body fragmentation [84]. Likewise, the mutation of Mov10l1 in round spermatids may also stimulate the deficiency of the piRNAs, resulting in severe DNA damages [84]. Similarly, the miR-122 synthesis in round spermatids participates in the process of post transcriptional down regulation of the transition protein 2 , through targeting the 3' untranslated region of the mRNA. The down regulation of miR-122 is a feature of the asthenozoospermia or the oligoasthenozoospermia [85]. In the later stages of spermatogenesis, a decreased expression of the testicular miR-383 could inhibit the tumour suppressor, an interferon regulatory factor-1 (IRF1), which may provoke the male infertility and testicular germ cell tumour [86]. In addition, there are some diseases involving several types of miRNA. For example, levels of the miR-34c-5p, miR-122, miR-146b5p, miR-181a, miR-374b, miR-509-5p, and miR-513a-5p are significantly lower in patients with the azoospermia and higher in patients with the asthenozoospermia [87]. There are also some proteins that are required for the maturation of ncRNAs, while abnormalities in such protein expression may lead to some diseases. For instance, the ablation of Dicer in the Sertoli cells is associated with infertility due to the complete absence of sperm and testis degenerations [88]. The knockout of the Miwi gene is shown to result in the spermiogenic arrest [89]. Similarly, knockout of the Mili and Miwi2 could lead to the meiotic arrest $[90,91]$.

In addition, the sperm miRNAs can be transmitted to embryos following the fertilisation, and the altered profiles of miRNAs in sperm may result in an abnormal embryonic development. For example, the inhibition of the miR-34c can suppress the DNA synthesis and arrest the embryo at the first cleavage division [32]. Simultaneous inactivation of the $m i R-34 \mathrm{~b} / \mathrm{c}$ and $m i R-449$ would cause sexually dimorphic, partial perinatal lethality, growth retardation, and infertility [92]. Apart from the sperm miRNAs, the seminal miRNAs that are mainly derived from the testis and epididymis are also believed to be useful noninvasive biomarkers for the identification of the impaired sperm production and maturation [93]. For example, in the seminal plasma of patients with nonobstructive azoospermia the levels of the three miRNAs - miR-141, miR-429 and miR-7-1-3p - were found to be increased, compared with the fertile controls [94].

It is apparent that the alterations of miRNAs and piRNAs play key roles in the reproductive diseases, and the lncRNAs are a new addition to the ncRNAs family. LncRNAs transcription and processing are complicated, whilst the majority of them are localized in the nucleus, suggesting that they may be involved in the regulation of chromatin. For example, a decreased expression of HOTAIR may reduce $\mathrm{H} 4$ acetylation in $\mathrm{Nrf} 2$ promoter and Nrf2 expression, which is closely associated with asthenozoospermia and oligoasthenozoospermia [95]. Moreover, the accumulation of NLC1-C in the nucleus of spermatogonia and primary spermatocytes represses both miR-320a and miR-383 transcription by binding to Nucleolin, resulting in hyperactive proliferation of germ cells and further leading to male infertility [96]. These lncRNAs in the genome have numerous intrinsic messages and future research efforts should identify and characterize the lncRNAs that are actively involved in the events of spermatogenesis and embryogenesis in detail.

\section{Abnormal proportion of protamines associated with reduced male fertility}

Protamines are critical for the proper chromatin packing. The variations in sperm protamine expression and ratio have been shown to be associated with the precocious chromatin condensation, the increase in the DNA fragmentation, the lower sperm counts and reduced fertilising capacity, which lead to the embryonic arrest (Table 4) [97].

The protamine $1(\mathrm{P} 1)$ and protamine $2(\mathrm{P} 2)$ are usually expressed in nearly equal quantities [98]. Kempisty et al. have shown that lower levels of the P1 and $\mathrm{P} 2$ transcripts or the $\mathrm{P} 1 / \mathrm{P} 2$ ratio exist in the ejaculated sperm of asthenozoospermic men, and believed that they were associated with the abnormal retention of the protamine mRNA, which is known to increase the DNA fragmentation level [53, 99]. Simon et al. have shown that the abnormally high or low $\mathrm{P} 1 / \mathrm{P} 2$ ratios may result in 
an increased sperm DNA fragmentation [97]. Meanwhile, the down regulation or haploinsufficiency of protamines can induce the precocious chromatin condensation, transcription arrest, spermatogenic failure and lowered sperm counts [100]. Currently, as it is easy to measure, the $\mathrm{P} 1 / \mathrm{P} 2$ ratio is widely used as a marker of abnormal spermiogenesis [100]. In addition, reports from many laboratories have shown that a change in the $\mathrm{P} 1 / \mathrm{P} 2$ ratio is not only associated with the altered sperm quality, but also with the decreased embryo quality and the IVF outcomes, when compared with infertile patients with a normal P1/ P2 ratio. de Mateo et al. have found that an abnormal protamine replacement can reduce the pregnancy rate [98].

In addition, the histone to protamine ratio can be used directly to detect aberrations in the histone retention, which has connections with the male infertility. The depletion of P2 leads not only to impaired histone to protamine exchange and disturbed DNAhypercondensation, but also to severe membrane defects resulting in immotility [101]. In addition, the DNA damage in a murine sperm was associated with the lower P2 concentration and the embryonic arrest was observed when such sperm was used to fertilise an oocyte through an intracytoplasmic sperm injection [5]. These results indicate that protamines may have a greater role in the spermatogenesis and in the early embryo development than previously have believed [1].

\section{CONCLUSION AND PERSPECTIVES}

It is apparent that the dynamics of epigenetic modifications and their regulatory networks are essential for the normal spermatogenesis and embryogenesis processes. The perturbations in any such modifications are likely to cause some degrees of infertility, and the altered epigenetic marks could be inherited and further result in phenotypic defects in the offspring [102]. For instance, a high-fat or low-protein diet in male mice can alter the metabolic gene expression in the offspring, which is mediated by the small noncoding RNAs derived from the transition RNAs [103, 104]. Moreover, it seems more obvious that various altered epigenetic modifications associated with reproductive diseases are all linked together. Clearly, abnormal DNA methylation are in fact associated with altered histone modifications, dysregulation of ncRNAs as well as dysfunctions of protamination, and all of them contribute to male infertility in some degree. Therefore, the research on epigenetic alterations in sperm and embryos is essential for us to understand the pathogenesis of reproductive diseases and develop the novel approaches and applications in the treatment of male infertility and offspring diseases. However, an association between the epigenetic landscape of a given regulatory element, male infertility and embryonic defects is still evolving, and numerous clinical effects of abnormal epigenetic modifications remain to be fully investigated. It is necessary to elucidate the interplay mechanisms for epigenetic modifications, and determine the best timeframe to reverse the deviant epigenetic marks.

Satisfyingly, the epigenetic editing system has represented a powerful toolbox that can be used to drastically modify the epigenetic landscape of a specific regulatory element, and this useful technique may be readily adopted in gene and cell therapies $[105$, 106]. Meanwhile, identifying specific enzymes for the modulation of abnormal epigenetic marks is also essential for the development of epigenetic drugs that can be used for treatments at the body level. We believe that a highly efficient and specific epigenetic therapy will be an important milestone for the development of precision medicines.

\section{Author contributions}

S.-Q.G designed the study, identified the articles, and drafted and revised the manuscript. Q.-Y.S. designed the study and revised the manuscript. S.-L. L and Z.-H.Z edited and revised the manuscript. All authors approved the final version of the manuscript.

\section{ACKNOWLEDGMENTS}

This work was supported by National Natural Science Foundation of China (31472055), the Hebei Province Natural Science Foundation of China (H2013201259).

\section{CONFLICTS OF INTEREST}

The authors declare that they have no conflicts of interest.

\section{REFERENCES}

1. Carrell DT, Hammoud SS. The human sperm epigenome and its potential role in embryonic development. Mol Hum Reprod. 2010; 16: 37-47.

2. Carrell DT. Epigenetics of the male gamete. Fertil Steril. 2012; 97: 267-274.

3. Gannon JR, Emery BR, Jenkins TG, Carrell DT. The sperm epigenome: implications for the embryo. Adv Exp Med Biol. 2014; 791: 53-66.

4. Jenkins TG, Carrell DT. The paternal epigenome and embryogenesis: poising mechanisms for development. Asian J Androl. 2011; 13: 76-80.

5. Cho C, Jung-Ha H, Willis WD, Goulding EH, Stein P, $\mathrm{Xu}$ Z, Schultz RM, Hecht NB, Eddy EM. Protamine 2 deficiency leads to sperm DNA damage and embryo death in mice. Biol Reprod. 2003; 69: 211-217. 
6. Aston KI, Punj V, Liu L, Carrell DT. Genome-wide sperm deoxyribonucleic acid methylation is altered in some men with abnormal chromatin packaging or poor in vitro fertilization embryogenesis. Fertil Steril. 2012; 97: 285-292.

7. Shirakata Y, Hiradate Y, Inoue H, Sato E, Tanemura K. Histone $\mathrm{H} 4$ modification during mouse spermatogenesis. J Reprod Dev. 2014; 60: 383-387.

8. Matsuzaki H, Okamura E, Takahashi T, Ushiki A, Nakamura T, Nakano T, Hata K, Fukamizu A, Tanimoto K. De novo DNA methylation through the 5'-segment of the H19 ICR maintains its imprint during early embryogenesis. Development. 2015; 142: 3833-3844.

9. Herman JG, Baylin SB. Gene silencing in cancer in association with promoter hypermethylation. New Engl $\mathrm{J}$ Med. 2003; 349: 2042-2054.

10. Capra JA. Extrapolating histone marks across developmental stages, tissues, and species: an enhancer prediction case study. BMC Genomics. 2015; 16: 104.

11. Deaton AM, Bird A. CpG islands and the regulation of transcription. Genes Dev. 2011; 25: 1010-1022.

12. Jones PA. Functions of DNA methylation: islands, start sites, gene bodies and beyond. Nat Rev Genet. 2012; 13: 484-492.

13. Bird A. DNA methylation patterns and epigenetic memory. Genes Dev. 2002; 16: 6-21.

14. Tang WW, Kobayashi T, Irie N, Dietmann S, Surani MA. Specification and epigenetic programming of the human germ line. Nat Rev Genet. 2016; 17: 585-600.

15. Biermann K, Steger K. Epigenetics in male germ cells. J Androl. 2007; 28: 466-480.

16. Rose NR, Klose RJ. Understanding the relationship between DNA methylation and histone lysine methylation. Biochim Biophys Acta. 2014; 1839: 1362-1372.

17. Guo X, Wang L, Li J, Ding Z, Xiao J, Yin X, He S, Shi P, Dong L, Li G, Tian C, Wang J, Cong Y, et al. Structural insight into autoinhibition and histone $\mathrm{H} 3$-induced activation of DNMT3A. Nature. 2015; 517: 640-644.

18. Santos F, Peters AH, Otte AP, Reik W, Dean W. Dynamic chromatin modifications characterise the first cell cycle in mouse embryos. Dev Biol. 2005; 280: 225-236.

19. Carone BR, Hung JH, Hainer SJ, Chou MT, Carone DM, Weng Z, Fazzio TG, Rando OJ. High-resolution mapping of chromatin packaging in mouse embryonic stem cells and sperm. Dev Cell. 2014; 30: 11-22.

20. Zhao Q, Zhang J, Chen R, Wang L, Li B, Cheng H, Duan X, Zhu H, Wei W, Li J, Wu Q, Han JD, Yu W, et al. Dissecting the precise role of $\mathrm{H} 3 \mathrm{~K} 9$ methylation in crosstalk with DNA maintenance methylation in mammals. Nat Commun. 2016; 7: 12464.

21. Sadakierska-Chudy A, Filip M. A comprehensive view of the epigenetic landscape. Part II: Histone post-translational modification, nucleosome level, and chromatin regulation by ncRNAs. Neurotox Res. 2015; 27: 172-197.

22. Kouzarides T. Chromatin modifications and their function.
Cell. 2007; 128: 693-705.

23. Dahl JA, Jung I, Aanes H, Greggains GD, Manaf A, Lerdrup M, Li G, Kuan S, Li B, Lee AY, Preissl S, Jermstad I, Haugen $\mathrm{MH}$, et al. Broad histone H3K4me3 domains in mouse oocytes modulate maternal-to-zygotic transition. Nature. 2016; 537: 548-552.

24. Zhang B, Zheng H, Huang B, Li W, Xiang Y, Peng X, Ming J, Wu X, Zhang Y, Xu Q, Liu W, Kou X, Zhao Y, et al. Allelic reprogramming of the histone modification H3K4me3 in early mammalian development. Nature. 2016; 537: 553-557.

25. Liu X, Wang C, Liu W, Li J, Li C, Kou X, Chen J, Zhao Y, Gao H, Wang H, Zhang Y, Gao Y, Gao S. Distinct features of H3K4me3 and H3K27me3 chromatin domains in preimplantation embryos. Nature. 2016; 537: 558-562.

26. Jodar M, Selvaraju S, Sendler E, Diamond MP, Krawetz SA. The presence, role and clinical use of spermatozoal RNAs. Hum Reprod Update. 2013; 19: 604-624.

27. de Mateo S, Sassone-Corsi P. Regulation of spermatogenesis by small non-coding RNAs: Role of the germ granule. Semin Cell Dev Biol. 2014; 29: 84-92.

28. Yadav RP, Kotaja N. Small RNAs in spermatogenesis. Mol Cell Endocrinol. 2014; 382: 498-508.

29. Cicchini C, de Nonno V, Battistelli C, Cozzolino AM, De Santis Puzzonia M, Ciafrè SA, Brocker C, Gonzalez FJ, Amicone L, Tripodi M. Epigenetic control of EMT/MET dynamics: HNF4 $\alpha$ impacts DNMT3s through miRs-29. Biochim Biophys Acta. 2015; 1849: 919-929.

30. Dai L, Tsai-Morris CH, Sato H, Villar J, Kang JH, Zhang J, Dufau ML. Testis-specific miRNA-469 up-regulated in gonadotropin-regulated testicular RNA helicase (GRTH/DDX25)-null mice silences transition protein 2 and protamine 2 messages at sites within coding region: implications of its role in germ cell development. J Biol Chem. 2011; 286: 44306-44318.

31. Yuan S, Schuster A, Tang C, Yu T, Ortogero N, Bao J, Zheng H, Yan W. Sperm-borne miRNAs and endosiRNAs are important for fertilization and preimplantation embryonic development. Development. 2016; 143: 635647.

32. Liu WM, Pang RT, Chiu PC, Wong BP, Lao K, Lee KF, Yeung WS. Sperm-borne microRNA-34c is required for the first cleavage division in mouse. Proc Natl Acad Sci USA. 2012; 109: 490-494.

33. Grow EJ, Flynn RA, Chavez SL, Bayless NL, Wossidlo M, Wesche DJ, Martin L, Ware CB, Blish CA, Chang HY, Pera RA, Wysocka J. Intrinsic retroviral reactivation in human preimplantation embryos and pluripotent cells. Nature. 2015; 522: 221-225.

34. Luo LF, Hou CC, Yang WX. Small non-coding RNAs and their associated proteins in spermatogenesis. Gene. 2016; 578: 141-157.

35. Russell SJ, Stalker L, Gilchrist G, Backx A, Molledo G, Foster RA, LaMarre J. Identification of PIWIL1 isoforms 
and their expression in bovine testes, oocytes and early embryos. Biol Reprod. 2016; 94: 75.

36. Chuma S, Nakano T. piRNA and spermatogenesis in mice. Philos Trans R Soc Lond B Biol Sci. 2013; 368: 20110338.

37. Cordaux R, Batzer MA. The impact of retrotransposons on human genome evolution. Nat Rev Genet. 2009; 10: 691703.

38. Tang WW, Kobayashi T, Irie N, Dietmann S, Surani MA. Specification and epigenetic programming of the human germ line. Nat Rev Genet. 2016; 17: 585-600.

39. Evsikov AV, Marín de Evsikova C. Friend or Foe: Epigenetic regulation of retrotransposons in mammalian oogenesis and early development. Yale J Biol Med. 2016; 89: 487-497.

40. Schagdarsurengin U, Steger K. Epigenetics in male reproduction: effect of paternal diet on sperm quality and offspring health. Nat Rev Urol. 2016; 13: 584-595.

41. Aravin AA, Sachidanandam R, Bourchis D, Schaefer C, Pezic D, Toth KF, Bestor T, Hannon GJ. A piRNA pathway primed by individual transposons is linked to de novo DNA methylation in mice. Mol Cell. 2008; 31: 785-799.

42. Stalker L, Russell SJ, Co C, Foster RA, LaMarre J. PIWIL1 is expressed in the canine testis, increases with sexual maturity and binds small RNAs. Biol Reprod. 2016; 94: 17.

43. Bui LC, Evsikov AV, Khan DR, Archilla C, Peynot N, Henaut A, Le Bourhis D, Vignon X, Renard JP, Duranthon $\mathrm{V}$. Retrotransposon expression as a defining event of genome reprograming in fertilized and cloned bovine embryos. Reproduction. 2009; 138: 289-299.

44. Sillaste G, Kaplinski L, Meier R, Jaakma Ü, Eriste E, Salumets A. A novel hypothesis for histone-to-protamine transition in Bos taurus spermatozoa. Reproduction. 2017; 153: 241-251.

45. Brunner AM, Nanni P, Mansuy IM. Epigenetic marking of sperm by post-translational modification of histones and protamines. Epigenetics Chromatin. 2014; 7: 2.

46. Brykczynska U, Hisano M, Erkek S, Ramos L, Oakeley EJ, Roloff TC, Beisel C, Schübeler D, Stadler MB, Peters AH. Repressive and active histone methylation mark distinct promoters in human and mouse spermatozoa. Nat Struct Mol Biol. 2010; 17: 679-687.

47. Casas E, Vavouri T. Sperm epigenomics: challenges and opportunities. Front Genet. 2014; 5: 330.

48. Ihara M, Meyer-Ficca ML, Leu NA, Rao S, Li F, Gregory BD, Zalenskaya IA, Schultz RM, Meyer RG. Paternal poly (ADP-ribose) metabolism modulates retention of inheritable sperm histones and early embryonic gene expression. PLoS Genet. 2014; 10: e1004317.

49. Erkek S, Hisano M, Liang CY, Gill M, Murr R, Dieker J, Schübeler D, van der Vlag J, Stadler MB, Peters AH. Molecular determinants of nucleosome retention at $\mathrm{CpG}$ rich sequences in mouse spermatozoa. Nat Struct Mol Biol. 2013; 20: 868-875.

50. Rathke C, Baarends WM, Awe S, Renkawitz-Pohl R.
Chromatin dynamics during spermiogenesis. Biochim Biophys Acta. 2014; 1839: 155-168.

51. Carrell DT, Emery BR, Hammoud S. Altered protamine expression and diminished spermatogenesis: what is the link? Hum Reprod Update. 2007; 13: 313-327.

52. Mukherjee S, Hao YH, Orth K. A newly discovered posttranslational modification-the acetylation of serine and threonine residues. Trends Biochem Sci. 2007; 32: 210-216.

53. Aoki VW, Emery BR, Carrell DT. Global sperm deoxyribonucleic acid methylation is unaffected in protamine-deficient infertile males. Fertil Steril. 2006; 86: 1541-1543.

54. Eroglu A, Layman LC. Role of ART in Imprinting Disorders. Semin Reprod Med. 2012; 30: 92-104.

55. Cooper WN, Luharia A, Evans GA, Raza H, Haire AC, Grundy R, Bowdin SC, Riccio A, Sebastio G, Bliek J, Schofield PN, Reik W, Macdonald F, et al. Molecular subtypes and phenotypic expression of BeckwithWiedemann syndrome. Eur J Hum Genet. 2005; 13: 1025 1032.

56. Ferreira HJ, Heyn H, Garcia del Muro X, Vidal A, Larriba S, Muñoz C, Villanueva A, Esteller M. Epigenetic loss of the PIWI/piRNA machinery in human testicular tumorigenesis. Epigenetics. 2014; 9: 113-118.

57. Khazamipour N, Noruzinia M, Fatehmanesh P, Keyhanee M, Pujol P. MTHFR promoter hypermethylation in testicular biopsies of patients with non-obstructive azoospermia: the role of epigenetics in male infertility. Hum Reprod. 2009; 24: 2361-2364.

58. Wu W, Shen O, Qin Y, Niu X, Lu C, Xia Y, Song L, Wang S, Wang X. Idiopathic male infertility is strongly associated with aberrant promoter methylation of Methylenetetrahydrofolate Reductase (MTHFR). PLoS One. 2010; 5: e13884.

59. Karaca MZ, Konac E, Yurteri B, Bozdag G, Sogutdelen E, Bilen CY. Associaton between methylenetetrahydrofolate reductase (MTHFR) gene promoter hypermethylaton and the risk of idiopathic male infertility. Andrologia. 2016 Sep 5. doi: 10.1111/and.12698. [Epub ahead of print].

60. Xu A, Hua Y, Zhang J, Chen W, Zhao K, Xi W. Abnormal hypermethylation of the VDAC2 promoter is a potential cause of idiopathic asthenospermia in men. Sci Rep. 2016; 6: 37836

61. Dada R, Kumar M, Jesudasan R, Fernández JL, Gosálvez J, Agarwal A. Epigenetics and its role in male infertility. J Assist Reprod Genet. 2012; 29: 213-223.

62. Verdyck P, Berckmoes V, De Vos A, Verpoest W, Liebaers I, Bonduelle M, De Rycke M. Chromosome fragility at FRAXA in human cleavage stage embryos at risk for fragile X syndrome. Am J Med Genet A. 2015; 167: 2306-2313.

63. Zhou Y, Kumari D, Sciascia N, Usdin K. CGG-repeat dynamics and FMR1 gene silencing in fragile $\mathrm{X}$ syndrome stem cells and stem cell-derived neurons. Mol Autism. 2016; 7: 42 . 
64. Kaneda M, Okano M, Hata K, Sado T, Tsujimoto N, Li E, Sasaki H. Essential role for de novo DNA methyltransferase Dnmt3a in paternal and maternal imprinting. Nature. 2004; 429: 900-903

65. La Salle S, Oakes CC, Neaga OR, Bourc'his D, Bestor TH, Trasler JM. Loss of spermatogonia and wide-spread DNA methylation defects in newborn malemice deficient in DNMT3L. BMC Dev Biol. 2007; 7: 104.

66. Kato Y, Kaneda M, Hata K, Kumaki K, Hisano M, Kohara Y, Okano M, Li E, Nozaki M, Sasaki H. Role of the Dnmt3 family inde novomethylation of imprinted and repetitive sequences during male germ cell development in the mouse. Hum Mol Genet. 2007; 16: 2272-2280.

67. Almstrup K, Hoei-Hansen CE, Nielsen JE, Wirkner U, Ansorge W, Skakkebaek NE, Rajpert-De Meyts E, Leffers H. Genomewide gene expression profiling of testicular carcinoma in situ progression into overt tumours. Br J Cancer. 2005; 92: 1934-1941.

68. Bourc'his D, Xu GL, Lin CS, Bollman B, Bestor, Timothy H. Dnmt3L and the establishment of maternal genomic imprints. Science. 2001; 294: 2536-2539.

69. Glaser S, Lubitz S, Loveland KL, Ohbo K, Robb L, Schwenk F, Seibler J, Roellig D, Kranz A, Anastassiadis $\mathrm{K}$, Stewart AF. The histone 3 lysine 4 methyltransferase, M112, is only required briefly in development and spermatogenesis. Epigenetics Chromatin. 2009; 2: 5.

70. Shi Y, Lan F, Matson C, Mulligan P, Whetstine JR, Cole PA, Casero RA, Shi Y. Histone demethylation mediated by the nuclear amine oxidase homolog LSD1. Cell. 2004; 119: 941-953.

71. Najafipour R, Moghbelinejad S, Samimi Hashjin A, Rajaei F, Rashvand Z. Evaluation of mRNA contents of YBX2 and JHDM2A genes on testicular tissues of azoospermic men with different classes of spermatogenesis. Cell J. 2015; 17: 121-128.

72. Lu LY, Wu J, Ye L, Gavrilina GB, Saunders TL, Yu $\mathrm{X}$. RNF8-dependent histone modifications regulate nucleosome removal during spermatogenesis. Dev Cell. 2010; 18: 371-384.

73. Zhuang T, Hess RA, Kolla V, Higashi M, Raabe TD, Brodeur GM. CHD5 is required for spermiogenesis and chromatin condensation. Mech Dev. 2014; 131: 35-46.

74. Xiong J, Wang H, Guo G, Wang S, He L, Chen H, Wu J. Male germ cell apoptosis and epigenetic histone modification induced by Tripterygium wilfordii Hook F. PLoS One. 2011; 6: e20751.

75. Paradowska AS, Miller D, Spiess AN, Vieweg M, Cerna M, Dvorakova-Hortova K, Bartkuhn M, Schuppe HC, Weidner W, Steger K. Genome wide identification of promoter binding sites for H4K12ac in human sperm and its relevance for early embryonic development. Epigenetics. 2012; 7: 1057-1070.

76. Glanzner WG, Wachter A, Coutinho AR, Albornoz MS, Duggavathi R, GonÇAlves PB. Altered expression of BRG1 and histone demethylases, and aberrant $\mathrm{H} 3 \mathrm{~K} 4$ methylation in less developmentally competent embryos at the time of embryonic genome activation. Mol Reprod Dev. 2017; 84: 19-29.

77. Dodge JE, Kang YK, Beppu H, Lei H, Li E. Histone H3-K9 methyltransferase ESET is essential for early development. Mol Cell Biol. 2004; 24: 2478-2486.

78. Ausio J, Levin DB, De Amorim GV, Bakker S, Macleod PM. Syndromes of disordered chromatin remodeling. Clin Genet. 2003; 64: 83-95.

79. Kotaja N. MicroRNAs and spermatogenesis. Fertil Steril. 2014; 101: 1552-1562.

80. Marcet B, Chevalier B, Luxardi G, Coraux C, Zaragosi LE, Cibois M, Robbe-Sermesant K, Jolly T, Cardinaud B, Moreilhon C, Giovannini-Chami L, Nawrocki-Raby B, Birembaut $\mathrm{P}$, et al. Control of vertebrate multiciliogenesis by miR-449 through direct repression of the Delta/Notch pathway. Nat Cell Biol. 2011; 13: 693-699.

81. Hoja MR, Liu JG, Mohammadieh M, Kvist U, Yuan L. E2F1 deficiency impairs murine spermatogenesis and augments testicular degeneration in SCP3-nullizygous mice. Cell Death Differ. 2004; 11: 354-356.

82. Comazzetto S, Di Giacomo M, Rasmussen KD, Much C, Azzi C, Perlas E, Morgan M, O’Carroll D. Oligoasthenoteratozoospermia and infertility in mice deficient for miR-34b/c and miR-449 loci. PLoS Genet. 2014; 10: e1004597.

83. Romero Y, Meikar O, Papaioannou MD, Conne B, Grey C, Weier M, Pralong F, De Massy B, Kaessmann H, Vassalli JD, Kotaja N, Nef S. Dicer1 depletion in male germ cells leads to infertility due to cumulative meiotic and spermiogenic defects. PLoS One. 2011; 6: e25241.

84. Zheng $\mathrm{K}$, Wang PJ. Blockade of pachytene piRNA biogenesis reveals a novel requirement for maintaining post-meiotic germline genome integrity. PLos Genet. 2012; 8: e1003038.

85. Abu-Halima M, Hammadeh M, Schmitt J, Leidinger P, Keller A, Meese E, Backes C. Altered microRNA expression profiles of human spermatozoa in patients with different spermatogenic impairments. Fertil Steril. 2013; 99: 1249-1255.

86. Lian J, Tian H, Liu L, Zhang XS, Li WQ, Deng YM, Yao GD, Yin MM, Sun F. Down regulation of microRNA-383 is associated with male infertility and promotes testicular embryonal carcinoma cell proliferation by targeting IRF1. Cell Death Dis. 2010; 1: e94.

87. Wang C, Yang C, Chen X, Yao B, Yang C, Zhu C, Li L, Wang J, Li X, Shao Y, Liu Y, Ji J, Zhang J, et al. Altered profile of seminal plasma microRNAs in the molecular diagnosis of male infertility. Clin Chem. 2011; 57: 17221731.

88. Papaioannou MD, Pitetti JL, Ro S, Park C, Aubry F, Schaad O, Vejnar CE, Kühne F, Descombes P, Zdobnov EM, McManus MT, Guillou F, Harfe BD, et al. Sertoli cell 
Dicer is essential for spermatogenesis in mice. Dev Biol. 2009; 326: 250-259.

89. Deng W, Lin H. miwi, a murine homolog of piwi, encodes a cytoplasmic protein essential for spermatogenesis. Dev Cell. 2002; 2: 819-830.

90. Kuramochi-Miyagawa S, Kimura T, Ijiri TW, Isobe T, Asada N, Fujita Y, Ikawa M, Iwai N, Okabe M, Deng W, Lin H, Matsuda Y, Nakano T. Mili, a mammalian member of piwi family gene, is essential for spermatogenesis. Development. 2004; 131: 839-849.

91. Carmell MA, Girard A, van de Kant HJ, Bourc'his D, Bestor TH, de Rooij DG, Hannon GJ. MIWI2 is essential for spermatogenesis and repression of transposons in the mouse male germline. Dev Cell. 2007; 12: 503-514.

92. Wu J, Bao J, Kim M, Yuan S, Tang C, Zheng H, Mastick GS, Xu C, Yan W. Two miRNA clusters, miR-34b/c and miR-449, essential for normal brain development, motile ciliogenesis, and spermatogenesis. Proc Natl Acad Sci U S A. 2014; 111: E2851-E2857.

93. $\mathrm{Hu} \mathrm{L}, \mathrm{Wu} \mathrm{C}$, Guo C, Li H, Xiong C. Identification of microRNAs predominately derived from testis and epididymis in human seminal plasma. Clin Biochem. 2014; 47: 967-972.

94. Wu W, Qin Y, Li Z, Dong J, Dai J, Lu C, Guo X, Zhao Y, Zhu Y, Zhang W, Hang B, Sha J, Shen H, et al. Genomewide microRNA expression profiling in idiopathic nonobstructive azoospermia: significant up-regulation of miR141, miR-429 and miR-7-1-3p. Hum Reprod. 2013; 28: 1827-1836.

95. Zhang L, Liu Z, Li X, Zhang P, Wang J, Zhu D, Chen X, Ye L. Low long non-coding RNA HOTAIR expression is associated with down-regulation of $\mathrm{Nrf2}$ in the spermatozoa of patients with asthenozoospermia or oligoasthenozoospermia. Int J Clin Exp Pathol. 2015; 8: 14198-14205.

96. Lü M, Tian H, Cao YX, He X, Chen L, Song X, Ping P, Huang H, Sun F. Downregulation of miR-320a/383-spongelike long non-coding RNA NLC1-C (narcolepsy candidateregion 1 genes) is associated with male infertility and promotes testicular embryonal carcinoma cell proliferation. Cell Death Dis. 2015; 6: e1960.
97. de Mateo S, Gázquez C, Guimerà M, Balasch J, Meistrich ML, Ballescà JL, Oliva R. Protamine 2 precursors (Pre$\mathrm{P} 2)$, protamine 1 to protamine 2 ratio (P1/P2), and assisted reproduction outcome. Fertil Steril. 2009; 91: 715-722.

98. Simon L, Castillo J, Oliva R, Lewis SE. Relationships between human sperm protamines, DNA damage and assisted reproduction outcomes. Reprod Biomed Online. 2011; 23: 724-734.

99. Kempisty B, Depa-Martynow M, Lianeri M, Jedrzejczak P, Darul-Wasowicz A, Jagodzinski PP. Evaluation of protamines 1 and 2 transcript contents in spermatozoa from asthenozoospermic men. Folia Histochem Cytobiol. 2007; 45: S109-113.

100. Castillo J, Simon L, de Mateo S, Lewis S, Oliva R. Protamine/DNA ratios and DNA damage in native and density gradient centrifugated sperm from infertile patients. J Androl. 2011; 32: 324-332.

101. Schneider S, Balbach M, Jan F Jikeli, Fietz D, Nettersheim D, Jostes S, Schmidt R, Kressin M, Bergmann M, Wachten D, Steger K, Schorle H. Re-visiting the protamine-2 locus: deletion, but not haploinsufciency, renders male mice infertile. Sci Rep. 2016; 6: 36764.

102. Leslie M. EPIGENETICS. Sperm RNA fragments modify offspring metabolism. Science. 2016; 351: 13.

103. Sharma U, Conine CC, Shea JM, Boskovic A, Derr AG, Bing XY, Belleannee C, Kucukural A, Serra RW, Sun F, Song L, Carone BR, Ricci EP, et al. Biogenesis and function of tRNA fragments during sperm maturation and fertilization in mammals. Science. 2016; 351: 391-396.

104. Chen Q, Yan M, Cao Z, Li X, Zhang Y, Shi J, Feng GH, Peng H, Zhang X, Zhang Y, Qian J, Duan E, Zhai Q, et al. Sperm tsRNAs contribute to intergenerational inheritance of an acquired metabolic disorder. Science. 2016; 351: 397 400.

105. Amabile A, Migliara A, Capasso P, Biffi M, Cittaro D, Naldini L, Lombardo A. Inheritable silencing of endogenous genes by hit-and-run targeted epigenetic editing. Cell. 2016; 167: 219-232.

106. Liu XS, Wu H, Ji X, Stelzer Y, Wu X, Czauderna S, Shu J, Dadon D, Young RA, Jaenisch R. Editing DNA methylation in the mammalian genome. Cell. 2016; 167: 233-247. 